\title{
Annotation
}

\section{What is asthma?}

While almost every paediatrician would agree that asthma is a very common condition in childhood, often underdiagnosed despite being a major cause of absence from school, ${ }^{1}$ it has never been satisfactorily defined. True, there have been a number of more or less satisfactory attempts by august bodies such as the Ciba Guest Symposium ${ }^{2}$ and the American Thoracic Society, ${ }^{3}$ and one of the most lucid attempts to explain the definition of asthma was that of Professor J G Scadding. ${ }^{4}$ He made the point that the disease should be characterised by its functional effect:

'Asthma is a disease characterised by wide variations over short periods of time in resistance to flow in intrapulmonary airways'.

Professor Scadding went on to point out that the definition can be amplified by comments on causative mechanisms where known. With typical clarity he also tackled the difficult question as to what constitutes 'wide variations' by suggesting that this means changes that are symptomatically and therapeutically important. This being so, what is the problem in defining asthma and why the need for this annotation?

Physicians treating adult patients have long been troubled by the fact that chronic airflow obstruction can be due to chronic bronchitis, emphysema, asthma, or any combination of these conditions, and that it is often very difficult to separate the components. Many patients with these types of chronic obstructive lung disease have symptomatic and therapeutic variations in their airflow obstruction without ever reverting to normal or near normal lung function. To make matters worse, adults with asthma not infrequently smoke or reside in polluted areas, and add an irreversible component to their disease. Finally, there are the occupational asthmas that can occur in anyone without any special predisposition to the disease ${ }^{5}$ and resolve after removal from the offending environment. For all these reasons and others, those treating adult patients can rarely agree on what constitutes asthma.

We paediatricians often feel rather smug about asthma and tell our colleagues that we cannot see what all the fuss is about since the diagnosis is perfectly straightforward in children. But is it? If we accept Professor Scadding's definition ${ }^{4}$ as a good starting point and also that the adult type of chronic obstructive lung disease probably never occurs in childhood, ${ }^{\circ}$ ' what paediatric conditions could be confused with asthma and in what ways can asthma seem to be something else?

\section{The wheezy infant}

Wheezing in the first few months of life is even more common than asthma in later childhood, ${ }^{8}$ and various epidemiological surveys have put the incidence at 11 to $12 \%$ or more of all infants, especially among those in day care centres. ${ }^{910}$ The disease often seems to be caused by an initial viral infection, and recent surveys suggest little if any relation to a family predisposition to asthma or allergic diseases. ${ }^{11-14}$ The problem for us is that clinically and radiologically the infant looks exactly like a little asthmatic, and most patients recover largely or completely over a week or so. Functionally, they have appreciable airways obstruction and this too has been shown to reverse. ${ }^{15}$ To complicate matters a considerable proportion-some 40 to $50 \%$ - of bronchiolitic infants continue to have further episodes of wheeze during early childhood, ${ }^{121416}$ and many of them display a moderate increase in bronchial reactivity to exercise or histamine..$^{12-14} 16$

So are these infants with bronchiolitis, especially those with recurrent wheezing, just little asthmatics and should they be treated as such? For the reasons discussed above and summarised more fully elsewhere $^{8}$ there seem to be epidemiological differences between these ex-bronchiolitic infants and classic, asthmatic children, though it must be admitted that the distinction is not as clear as one would wish. Therapeutically, the picture is much clearer, at least as far as the infants in the acute phase are concerned, since there is general agreement that they rarely if ever respond to bronchodilators or steroids. ${ }^{17-20}$ Recently, we have found (data in preparation) a considerable improvement in lung function in infants less than 1 year old with persistent wheezing after bronchiolitis who were treated with nebulised beclomethasone for two weeks in a randomised, double blind, crossover 
trial. Thus it seems fair to conclude that the infant with acute viral bronchiolitis is not an asthmatic, and is most unlikely to respond to antiasthmatic medication, but we must be cautious about our definition and approach to those infants who continue to wheeze subsequently. Following Scadding's approach $^{4}$ we could say that they have 'asthma following bronchiolitis' and we should use those clinical and laboratory criteria that we use for asthma when deciding on treatment. What is certainly needed are further well conducted prospective follow up studies.

\section{Wheezing with other diseases of childhood}

As with adults, there is no doubt that a reversible component of airflow obstruction accompanies other diseases of children. Thus many children with cystic fibrosis can improve their lung function very considerably in response to conventional treatment over a period of time, and some respond to bronchodilators or steroids in the rapid manner seen in asthma. ${ }^{21}$ In fact, it is fairly certain that some children with cystic fibrosis also have asthma, which is hardly surprising given the high frequency of asthma. ${ }^{22}$ The infant with cystic fibrosis not infrequently presents with a bronchiolitic type of illness and is often given antiasthmatic medications, despite evidence that theophyllines may produce adverse responses. $^{23}$

A more difficult problem diagnostically arises in those infants and children who seem to suffer major chronic impairment of lung function, usually as a result of an adenoviral infection, and who have pathologic bronchiolitis obliterans. ${ }^{24-6}$ These patients have chronic airflow obstruction which resembles that seen in adults with chronic obstructive lung disease and are often very badly handicapped. Since the clinical picture resembles severe, persistent asthma, they are almost inevitably submitted to repeated treatment trials of various combinations of antiasthmatic medications, including steroids, all with little or no effect, ${ }^{26}$ although the occasional child, like the adult with chronic obstructive lung disease, may respond partially. It is important to recognise these patients for what they are, and to realise that they do not have asthma in view of their failure to respond to proper antiasthmatic measures. In many cases, a lung biopsy is required to establish the correct diagnosis, and this is probably a small price to pay in order to avoid years of useless antiasthmatic medication.

Although beloved of every paediatric resident when faced with a troublesome wheezy child, $\alpha_{1}$ antitrypsin deficiency is very rare in childhood with only a very few reports of children with this type of chronic obstructive lung disease ${ }^{27-9}$ although it may cause neonatal liver disease. The Wilson-Mikity syndrome and bronchopulmonary dysplasia cause chronic airflow obstruction which improves slowly with time, but they do not readily get confused with asthma owing to their relation to prematurity and neonatal intensive care. It must be admitted that the most persistent wheezers with these disorders rarely escape a trial of antiasthmatic medication. On the whole they do not seem to respond to bronchodilators but there is some recent evidence that steroids may help some children with bronchopulmonary dysplasia ${ }^{30}$ Congenital lobar emphysema may be confused with asthma unless chest radiography is performed, and other rare congenital bronchial anomalies such as bronchomalacia ${ }^{31}$ are often confused for a time with asthma since the children are often wheezy on and off. Likewise, syndromes associated with defective mucus clearance and recurrent respiratory illness ${ }^{32}$ can easily be confused with asthma because the clinical picture is often variable and most 'chesty' children do indeed have asthma.

In some parts of the, world where the eating of nuts is popular, a common and dangerous problem is the misdiagnosis of an inhaled foreign body in the belief that the child has asthma. It must not be forgotten that the child who has inhaled a foreign body often wheezes, the wheeze may be heard equally well over both lungs and can be variable, especially if the foreign body is in the trachea. All these features can mimic asthma to some extent and the paediatrician who lightly diagnoses asthma in a child with a sudden onset of persistent symptoms who has never had any respiratory problems in the past does so at grave risk to the patient.

\section{The child with a cough}

In young children cough is a very prominent feature of asthma and may be far more obvious to the family than the wheeze. Very typical of cough due to asthma is that it is almost always more obvious at night and may also be noticed after exercise (exercise induced cough). If the doctor only accepts wheeze as indicating asthma many of these patients will be misdiagnosed as having 'bronchitis' or 'pneumonia', and this is probably responsible for much of the underdiagnosis of asthma shown in recent surveys of children. ${ }^{1}{ }^{33}$ Those patients presenting with cough who are able to undertake lung function tests, show changes in response to exercise indistinguishable from asthmatics. ${ }^{34}$ Scadding's definition of asthma ${ }^{4}$ refers to functional changes and does not mention symptoms, but many young children are unable to cooperate with lung 
function tests, and so we may have to rely on a careful history instead.

Many children suffering from asthma are misdiagnosed as having pneumonia because the attack often starts in response to a viral infection that causes fever, and because cough and auscultatory signs in the chest are considered to be the hallmark of pneumonia. To make matters worse the chest radiograph, if taken, may show transient infiltrates or atelectasis especially in the middle lobe or lingula and this may be misread as confirming pneumonia. Now, while any child may have one or possibly two attacks of pneumonia, recurrent pneumonia suggests a serious underlying pathology such as cystic fibrosis, sick cilia syndrome, immunodeficiency, inhaled foreign body, etc. Most children who are well built and have 'recurrent pneumonia' with periods of normal health between have asthma that has been overlooked.

In adult practice it is very helpful to the clinician to undertake lung function and bronchial provocation tests to help with the diagnosis of asthma. In the typical patient, there will be some evidence of airways obstruction at rest which is considerably relieved after the inhalation of a bronchodilator. When challenged by exercise, hyperventilation, histamine, or methylcholine, the asthmatic shows a degree of hyper-reactivity far greater than that seen in normal subjects. In older children, the same types of test can be used but this may be impossible with younger children. At one time it was believed that asthma could be defined by this characteristic bronchial hyper-reactivity but experience has shown that this is too simplistic. Some patients with asthma may fail to develop exercise induced asthma on testing while other patients with upper respiratory tract allergy may show increased responsiveness to histamine. Recent respiratory infections and air pollution can also increase bronchial responsiveness, even in normal subjects. ${ }^{35}$

\section{Definition of childhood asthma}

Taking the above discussion into consideration and accepting the general definition proposed by Scadding $^{4}$ we can attempt to formulate a definition of childhood asthma based on clinical and physiological criteria:

'Asthma in childhood is a disease characterised by wide variations over short periods of time in resistance to flow in intrapulmonary airways and manifest by recurrent attacks of cough or wheeze separated by symptom free intervals. The airflow obstruction and clinical symptoms are largely or completely reversed by treatment with bronchodilator drugs or steroids.'

No definition of asthma is perfect and this one must be interpreted with common sense. It is not intended to exclude the severe chronic asthmatic who never has symptom free intervals but whose airflow obstruction nevertheless fluctuates widely from time to time. Nor is it intended to include the child who has inhaled a foreign body just because he has stopped coughing for an hour or two. It should be noted that this definition would include most young children with recurrent post bronchiolitic wheezing, but not the infant during the initial attack. It is premature to be dogmatic about those with recurrent attacks in the first year of life until we know more about their response to treatment. The definition omits any mention of allergy since in some asthmatic children there is no evidence of an atopic predisposition, and often there is no evidence that allergic stimulation is responsible for the attacks. In conformity with Scadding's suggestion, ${ }^{4}$ a rider could be added about the aetiology of the asthma should it be definitely established. In the long run there is no substitute for clinical experience and sound judgement, but the working definition proposed above should help the paediatrician to consider the inclusion or exclusion of asthma as a likely diagnosis in the individual patient.

\section{Does it matter?}

When all is said and done, why bother to try to define a disease which most experienced paediatricians have little difficulty in recognising? There are a number of arguments in favour of having a standard working definition.

(1) The reported incidence of asthma in children varies very widely in different series, ${ }^{36}$ and there is little doubt that much of this variability is due to different criteria being used to define asthma. Unless we have a standard definition, we cannot undertake proper comparative epidemiological surveys and we cannot reach logical conclusions about the extent of the problem or the adequacy of services for the child with asthma. Without standardisation we cannot use reported differences in the incidence of asthma as clues to the aetiology of the disease.

(2) Unless asthma is clearly defined clinically, many children will not be diagnosed correctly as having the disease and will suffer as a consequence. These children are likely to receive many unnecessary courses of antibiotics and may well suffer chronic ill health which could be prevented by proper treatment. It is not yet certain whether or not proper treatment of childhood asthma reduces the risk of chronic obstructive lung disease in adult life.

(3) Unless asthma is clearly differentiated from other diseases of childhood with airflow obstruction, 
many children will receive unnecessary antiasthmatic medication, including steroids. Furthermore, the parents may not be given the true diagnosis and prognosis, which may well result in a great deal of anxiety. In some situations a mistaken diagnosis of asthma may be very dangerous.

No doubt there will be those who disagree with the approach to the definition of childhood asthma described, but if this annotation does nothing more than to stimulate constructive argument, our thinking about this difficult subject will have advanced.

\section{References}

${ }^{1}$ Anderson HR, Bailey PA, Cooper JS, Palmer JC, West S. Morbidity and school absence caused by asthma and wheezing illness. Arch Dis Child 1983;58:777-84.

2 Ciba Guest Symposium. Terminology, definitions and classification of chronic pulmonary emphysema and related conditions. Thorax 1959;14:286-99.

${ }^{3}$ American Thoracic Society. Definition and classifications of chronic bronchitis, asthma and pulmonary emphysema. Am Rev Respir Dis 1962;85:762-8.

4 Scadding JG. Definitions and clinical categories of asthma. In: Clark TJH, Godfrey S, eds. Asthma. 2nd ed. London: Chapman and Hall, 1983:1-11.

5 Butcher BT, Jones RN, O'Neil CE, et al. Longitudinal study of workers employed in the manufacture of toluene diisocyanate. Am Rev Respir Dis 1977;116:411-21.

6 Taussig LM, Smith SM, Blumenfeld R. Chronic bronchitis in childhood: what is it? Pediatrics 1981;67:1-5.

${ }^{7}$ Phelan PD. Does adult chronic obstructive lung disease really begin in childhood? $\mathrm{Br} J$ Dis Chest 1984;78:1-9.

${ }^{8}$ Godfrey S. The wheezy infant. In: Meadow SR, ed. Recent advances in paediatrics no. 7. Edinburgh: Churchill Livingstone, 1984:137-53.

9 Henderson FW, Clyde WA, Collier AM, et al. The etiologic and epidemiologic spectrum of bronchiolitis in pediatric practice. J Pediatr 1979;95:183-90.

${ }^{10}$ Denney FW, Collier AM, Henderson FW, Clyde WA. The epidemiology of bronchiolitis. Pediatr Res 1977;11:234-6.

11 Mok JYQ, Simpson H. Symptoms, atopy and bronchial reactivity after lower respiratory infection in infancy. Arch Dis Child 1984;59:299-305.

12 Sims DG, Downham MAPS, Gardner PS, Webb JKG, Weightman D. Study of 8 year old children with a history of respiratory syncytial virus bronchiolitis in infancy. Br Med J 1978;i:11-4.

13 Sims DG, Gardner PS, Weightman D, Turner MW, Soothill JF. Atopy does not predispose to RSV bronchiolitis or postbronchiolitic wheezing. Br Med $J$ 1981;282:2086-8.

14 Pullan CR, Hey EN. Wheezing, asthma and pulmonary dysfunction 10 years after infection with respiratory syncytial virus in infancy. Br Med $J$ 1982;284:1665-9.

15 Phelan PD, Williams HE, Freeman M. The disturbances of ventilation in acute viral bronchiolitis. Aust Paediatr $J$ 1968;4:96-104.

${ }^{16}$ Mok JYQ, Simpson H. Outcome of acute lower respiratory tract infection in infants: preliminary report of seven-year follow-up study. Br Med J 1982;285:333-7.
${ }^{17}$ Phelan P, Williams HE. Sympathomimetic drugs in acute viral bronchiolitis. Their effect on pulmonary resistance. Pediatrics 1969;44:493-7.

${ }^{18}$ Radford M. Effect of salbutamol in infants with wheezy bronchitis. Arch Dis Child 1975;50:535-8.

19 Lenney W, Milner AD. Alpha and beta adrenergic stimulants in bronchiolitis and wheezy bronchitis in children under 18 months of age. Arch Dis Child 1978;53:707-9.

${ }^{20}$ Leer JA, Bloomfield NJ, Green JL, et al. Corticosteroid treatment in bronchiolitis. A controlled, collaborative study in 297 infants and children. Am J Dis Child 1969;117:495-503.

21 Ormerod LP, Thomson RA, Anderson CM, Stableforth DE. Reversibility of airway obstruction in cystic fibrosis. Thorax 1980;35:768-72.

22 Asperen P van, Mellis CM, South RT, Simpson SJ. Bronchial reactivity in cystic fibrosis with normal pulmonary function. $\mathrm{Am}$ Rev Respir Dis 1981;135:815-9.

${ }^{23}$ Shapiro GG, Bamman J, Kanarek P, Bierman CW. The paradoxical effect of adrenergic and methylxanthine drugs in cystic fibrosis. Pediatrics 1976;58:740-3.

24 Becroft DMD. Bronchiolitis obliterans, bronchiectasis, and other sequelae of adenovirus type 21 infection in young children. J Clin Pathol 1971;24:72-82.

25 Warner JO, Marshall WC. Crippling lung disease after measles and adenovirus infection. $\mathrm{Br} J$ Dis Chest 1976;70:89-94.

${ }^{26}$ Hodges IGC, Milner AD, Groggins RC, Stores GM. Causes and management of bronchiolitis with chronic obstructive features. Arch Dis Child 1982;57:495-9.

${ }^{27}$ Houstek J, Copova M, Zapletal A, Tomasova H, Samanek M. Alpha-antitrypsin deficiency in a child with chronic lung disease. Chest 1973;64:773-6.

${ }^{28}$ Glasgow JFT, Lynch MJ, Hercz A, Levison H, Sass-Kortsak A. Alpha antitrypsin deficiency in association with both cirrhosis and chronic obstructive lung disease in two sibs. Am J Med 1973;54:181-94.

${ }^{29}$ Dunand P, Cropp JA, Middleton E. Severe obstructive lung disease in a 14-year old girl with alpha-1 antitrypsin deficiency. J Allergy Clin Immunol 1976;57:615-22.

30 Avery GB, Fletcher AB, Kaplan M, Brudno DS. Controlled trial of dexamethasone in respirator-dependent infants with bronchopulmonary dysplasia. Pediatrics 1985;75:106-11.

31 Godfrey S. Association between pectus excavatum and segmental bronchomalacia. J Pediatr 1980;96:649-52.

32 Davis PB, Hubbard van S, McCoy K, Taussig LM. Familial bronchiectasis. J Pediatr 1983;102:177-85.

33 Speight ANP, Lee DA, Hey EN. Underdiagnosis and undertreatment of asthma in childhood. Br Med J 1983;286:1253-6.

${ }^{34}$ Cloutier MM, Loughlin GM. Chronic cough in children: a manifestation of airway hyperreactivity. Pediatrics 1981;67: 6-12.

35 Boushey HA, Holtzman MJ, Sheller JR, Nadel JA. Bronchial hyperreactivity. Am Rev Respir Dis 1980;121:389-413.

${ }^{36}$ Gregg I. Epidemiological aspects. In: Clark TJH, Godfrey S, eds. Asthma. 2nd ed. London: Chapman and Hall, 1983:242-84.

S GodFrey

Department of Paediatrics, Hadassah University Hospital,

Jerusalem,

Israel 